\title{
25 vs. 27-gauge micro-incision vitrectomy surgery for visually significant macular membranes and full-thickness macular holes: a retrospective study
}

Gordon T. Brown * ${ }^{*}$, Sangeethabalasri Pugazhendhi, Robert M. Beardsley, John W. Karth, Peter A. Karth and Allan A. Hunter

\begin{abstract}
Background: To evaluate visual and safety outcomes for 25-gauge (25G) and 27-gauge (27G) micro-incision vitrectomy platforms (MIVS) for the treatment of epiretinal membrane and full-thickness macular holes.

Methods: Retrospective analysis of all patients who underwent internal limiting membrane (ILM) peel surgery from January 2017 through December 2018. 207 cases met the eligibility criteria for inclusion. Primary endpoint was postoperative Best-Corrected Distance Visual Acuity (BCVA) at 6 months.

Results: For all patients combined, mean logMAR BCVA improved from $0.57( \pm 0.40)$ to $0.37( \pm 0.36)$ post-operatively $(p<0.001)$. For $25 \mathrm{G}$ ERMs, logMAR BCVA improved from $0.51( \pm 0.28)$ to $0.30( \pm 0.25)$ post-operatively $(p<0.001)$. For 27G ERMs, logMAR BCVA improved from $0.33( \pm 0.28)$ to $0.28( \pm 0.27)$ post- operatively $(p=0.15)$. For $25 G$ FTMHs, logMAR BCVA improved from $0.87( \pm 0.48)$ to $0.51( \pm 0.44)$ post-operatively $(p<0.001)$. For $27 G$ FTMHs, logMAR BCVA changed from $0.89( \pm 0.47)$ to $0.96( \pm 0.60)$.

Conclusion: Final visual outcomes improved for both 25G and 27G ERM groups and the 25G FTMH group. Both 25G and $27 \mathrm{G}$ were safe and well tolerated MIVS platforms for the treatment of ERM and FTMH.
\end{abstract}

Keywords: 25-gauge, 27-gauge, Epiretinal membrane, Macular hole, Macular peel, Micro-incision vitrectomy surgery, MIVS

\section{Introduction}

Micro-Incision Vitrectomy Surgery (MIVS) offers an excellent safety profile for patients, while the newest 27 -gauge (27G) systems have potential additional safety and outcome benefits when compared to earlier MIVS platforms. This innovation towards progressively smaller instrumentation is playing a major role in the evolution of posterior segment surgery by allowing for decreased incision size and, possibly, less pain, [1, 2] fewer

${ }^{*}$ Correspondence: gordon.brown@aya.yale.edu

Oregon Eye Consultants LLC, 1550 Oak St, Suite 7, Eugene, OR 97401, USA post-surgical wound leaks and subsequently, faster recovery times [3-5] with a low risk of other post-operative complications (6-8). Specifically, multiple large cohort studies and a 2013 literature review concluded there was no increased risk of endophthalmitis when comparing MIVS to 20-gauge (20G) vitrectomy [9-12]. However, a recent meta-analysis highlighted a potential increased risk of endophthalmitis in $25 \mathrm{G}$ vs. 20G. The authors hypothesized early vertical sclerotomy (rather than beveled trocar incisions) and hypotony in post-operative fluid-filled eyes (without gas tamponade) were potential risk factors. [13] Since introduced in 2010 by Oshima et al. [14], the range of vitreoretinal conditions for which

(c) The Author(s) 2020. This article is licensed under a Creative Commons Attribution 4.0 International License, which permits use, sharing, adaptation, distribution and reproduction in any medium or format, as long as you give appropriate credit to the original author(s) and the source, provide a link to the Creative Commons licence, and indicate if changes were made. The images or other third party material in this article are included in the article's Creative Commons licence, unless indicated otherwise in a credit line to the material. If material is not included in the article's Creative Commons licence and your intended use is not permitted by statutory regulation or exceeds the permitted use, you will need to obtain permission directly from the copyright holder. To view a copy of this licence, visit http://creativeco mmons.org/licenses/by/4.0/. The Creative Commons Public Domain Dedication waiver (http://creativecommons.org/publicdomain/ zero/1.0/) applies to the data made available in this article, unless otherwise stated in a credit line to the data. 
27G instrumentation has been utilized is increasing, with many surgeons using $27 \mathrm{G}$ for macular epiretinal membrane (ERM) peels and full thickness macular holes (FTMH), as well as more complex cases such as proliferative vitreoretinopathy and retinal detachment repairs $[15$, $16]$.

Several prior studies have compared 27G with other MIVS systems for various indications and they generally suggest that key outcomes between 25-gauge (25G) and $27 \mathrm{G}$ are comparable [17-21]. However, it is worth noting that most of these studies have relatively small sample sizes and the majority have been conducted in patient populations in Europe or East Asia. Currently, most vitreoretinal surgeons in the US are still primarily operating with the $25 \mathrm{G}$ system. Given the relatively recent integration of $27 \mathrm{G}$ into clinical practice in the United States, more large scale studies are required. The purpose of this study is to compare visual and safety outcomes for the 25G vs 27G MIVS platforms in the treatment of ERM and FTMH.

\section{Methods}

This Institutional Review Board (IRB) approved single center retrospective study reviews surgical outcomes following 25G and 27G Pars Plana Vitrectomy (PPV) and Internal Limiting Membrane (ILM) peel surgeries for ERM and FTMH. The Oregon Eye Consultants, LLC database was searched using vitrectomy procedure codes for ERM (67041) and FTMH and ILM peel (both 67042). Charts of 379 patients who underwent surgery from January 2017 through December 2018 were reviewed. 207 cases met the eligibility criteria for inclusion (Table 1).
The primary endpoint was Best-Corrected Distance Visual Acuity (BCVA) after 6 months (mean follow-up $=5.9$ months). Secondary endpoints included intraocular pressure (IOP), post-operative complications (including need for repeat surgery), and Optical Coherence Tomography (OCT) for central foveal thickness (CFT) and macular volume (MV). Secondary efficiency measurements included surgical time.

Statistical analysis was performed with Microsoft Excel using t-tests or the Wilcoxon signed rank test when appropriate for dependent data, and a $p$-value of $<0.05$ was considered statistically significant. This research adhered to the tenets of the Declaration of Helsinki and a waiver of informed consent was granted by the IRB.

\section{Results}

The study included 207 eyes from 105 females and 96 males (mean age $72.6 \pm 8.9$; range $24-98$ years), Table 2 . 88 eyes were phakic and 119 were pseudophakic preoperatively. Of the 207 surgeries, 150 were for ERM and 57 for FTMH; PAK performed 102 surgeries, JWK 43, RMB 44 and AAH 18, respectively. For the ERM group, 102 surgeries were with $25 \mathrm{G}$ and 48 with 27G. For the FTMH group, 47 surgeries were with $25 \mathrm{G}$ and 10 with 27G. At baseline, there were no statistically significant differences in age, gender or pre-operative lens status between the 25G and 27G groups for ERM or FTMH. For the ERM cohort, there was a statistically significant difference in pre-operative BCVA between 25 and 27G groups (highlighted, Table 2). There were borderline but non-statistically significant differences between IOP and CFT in the ERM 25G and 27G groups.

Table 1 Eligibility criteria

\begin{tabular}{|c|c|}
\hline Inclusion & Exclusion \\
\hline Visually significant Epiretinal Membrane or Macular Hole & Ocular trauma in study eye \\
\hline Pre-operative OCT of the operative eye & History of amblyopia in study eye \\
\hline Post-operative OCT of the operative eye & History of complicated cataract surgery in study eye \\
\hline Pseudophakic or phakic patients & History of PPV in study eye \\
\hline Any surgical technique for ILM removal (forceps, loops, peel technique) & History of vitreous hemorrhage in study eye \\
\hline ILM stain with Brilliant Blue G or Indocyanine Green & $\begin{array}{l}\text { History of ocular diseases (i.e. retinal vascular occlusion, high myopia, glau- } \\
\text { coma, neoplastic, or chronic inflammatory disorders) }\end{array}$ \\
\hline Both eyes of a patient can be enrolled in study & $\begin{array}{l}\text { Patients with systemic diseases (i.e. uncontrolled HTN or DM) with ocular } \\
\text { evidence of complications (Diabetic Macular Edema, Non-Proliferative } \\
\text { Diabetic Retinopathy, Microaneurysms, Dot Blot Hemorrhages, Exudates, } \\
\text { Cotton Wool Spots) }\end{array}$ \\
\hline \multirow[t]{2}{*}{ Macular membrane peeling with contact lens with direct visualization } & $\begin{array}{l}\text { History of cataract surgery in study eye within } 3 \text { months to pre-operative } \\
\text { assessment }\end{array}$ \\
\hline & $\begin{array}{l}\text { History of YAG capsulotomy in study eye within } 1 \text { month of preoperative } \\
\text { assessment }\end{array}$ \\
\hline
\end{tabular}


Table 2 Baseline characteristics and mean pre-operative values

\begin{tabular}{|c|c|c|c|c|c|c|c|}
\hline & & \multicolumn{3}{|c|}{ ERM } & \multicolumn{3}{|c|}{ FTMH } \\
\hline & $\begin{array}{l}\text { Overall } \\
(n=207)\end{array}$ & $\begin{array}{l}25 G \\
(n=102)\end{array}$ & $\begin{array}{l}27 G \\
(n=48)\end{array}$ & $p$ Value & $\begin{array}{l}25 G \\
(n=47)\end{array}$ & $\begin{array}{l}27 G \\
(n=10)\end{array}$ & $p$ Value \\
\hline $\begin{array}{l}\text { Age }^{\dagger} \\
\text { Gender }^{\ddagger}\end{array}$ & 72.6 & 73.0 & 72.5 & 0.51 & 72.4 & 70.4 & 0.40 \\
\hline Male & 98 & 49 & 26 & 0.48 & 20 & 3 & 0.46 \\
\hline $\begin{array}{l}\text { Female } \\
\text { Lens Status }{ }^{\ddagger}\end{array}$ & 109 & 53 & 22 & & 27 & 7 & \\
\hline Phakic & 88 & 40 & 19 & 0.97 & 24 & 5 & 0.95 \\
\hline Pseudophakic & 119 & 62 & 29 & 0.91 & 23 & 5 & \\
\hline Pre-Op logMAR BCVA All ${ }^{+}$ & 0.57 & 0.51 & 0.33 & $<0.001$ & 0.87 & 0.89 & 0.83 \\
\hline Phakic & & 0.38 & 0.31 & 0.06 & 0.93 & 0.88 & 0.73 \\
\hline Pseudophakic & & 0.59 & 0.34 & $<0.001$ & 0.81 & 0.90 & 0.43 \\
\hline Pre-Op IOP $(\mathrm{mmHg})^{\dagger}$ & 14.32 & 14.12 & 15.32 & 0.07 & 13.83 & 13.9 & 0.86 \\
\hline Pre-Op CFT $(\mu m)^{+}$ & - & 424.38 & 464.15 & 0.05 & - & - & - \\
\hline Pre-Op Macular Volume $\left(\mathrm{mm}^{3}\right)^{\dagger}$ & - & 10.0 & 10.3 & 0.31 & - & - & - \\
\hline
\end{tabular}

$B C V A$ best corrected visual acuity, CFT central foveal thickness, ERM epiretinal membrane, FTMH full thickness macular hole, IOP intraocular pressure, 25G 25-gauge, 27G 27-gauge

a Mann-Whitney U Test

b Chi Squared Test

For all patients combined, mean logMAR BCVA improved from $0.57( \pm 0.40)$ to $0.37( \pm 0.36)$ post-operatively $(\mathrm{p}<0.001)$ (Table 3$)$. For $25 \mathrm{G}$ ERMs, logMAR BCVA improved from $0.51( \pm 0.28)$ to $0.30( \pm 0.25)$ post-operatively $(\mathrm{p}<0.001)$. For $27 \mathrm{G}$ ERMs, logMAR BCVA improved from $0.33( \pm 0.28)$ to $0.28( \pm 0.27)$ post-operatively $(\mathrm{p}=0.15)$. For $25 \mathrm{G}$ FTMHs, $\operatorname{logMAR}$ BCVA improved from $0.87( \pm 0.48)$ to $0.51( \pm 0.44)$ post-operatively $(\mathrm{p}<0.001)$. For $27 \mathrm{G}$ FTMHs, $\log M A R$ BCVA changed from $0.89( \pm 0.47)$ to $0.96( \pm 0.60)$.

For 25G ERM phakic patients only, mean $\log M A R$ BCVA improved from $0.38( \pm 0.2)$ to $0.30( \pm 0.29)$ $(p=0.09)$. For $27 \mathrm{G}$ ERM phakic patients only, mean logMAR BCVA changed from $0.31( \pm 0.3)$ to $0.34( \pm 0.31)$. For 25G ERM pseudophakic patients, mean logMAR BCVA improved from $0.59( \pm 0.3)$ to $0.30( \pm 0.22)$ $(\mathrm{p}<0.001)$. For $27 \mathrm{G}$ ERM pseudophakic patients, mean

Table 3 Comparison of baseline data and post-operative outcomes (mean values) (statistically significant results highlighted in italics)

\begin{tabular}{|c|c|c|c|c|c|}
\hline & \multirow[t]{2}{*}{ Overall $(n=207)$} & \multicolumn{2}{|l|}{ ERM } & \multicolumn{2}{|l|}{ FTMH } \\
\hline & & $25 G(n=102)$ & $27 G(n=48)$ & $25 G(n=47)$ & $27 G(n=10)$ \\
\hline Pre-Op logMAR BCVA All & 0.57 & 0.51 & 0.33 & 0.87 & 0.89 \\
\hline Phakic & & 0.38 & 0.31 & 0.93 & 0.88 \\
\hline Pseudophakic & & 0.59 & 0.34 & 0.81 & 0.90 \\
\hline Post-Op logMAR BCVA All & 0.37 & 0.30 & 0.28 & 0.51 & 0.96 \\
\hline Phakic & & 0.30 & 0.34 & 0.69 & 1.00 \\
\hline Pseudophakic & & 0.30 & 0.24 & 0.33 & 0.91 \\
\hline Pre-Op IOP (mmHg) & 14.32 & 14.12 & 15.45 & 13.83 & 13.9 \\
\hline Post-Op IOP & 14.59 & 14.62 & 16.42 & 13.38 & 16 \\
\hline Pre-Op CFT ( $\mu m)$ & - & 424.38 & 464.15 & - & - \\
\hline Post-Op CFT ( $\mu \mathrm{m})$ & - & 358.58 & 394.37 & - & - \\
\hline Pre-Op macular volume $\left(\mathrm{mm}^{3}\right)$ & - & 10.0 & 10.3 & - & - \\
\hline Post-Op macular volume $\left(\mathrm{mm}^{3}\right)$ & - & 8.86 & 9.08 & - & - \\
\hline Surgical time-all data (mins) & 27 & 26 & 22.1 & 32.5 & 36.7 \\
\hline Surgical time-modified (mins) & 27 & 26 & 22.1 & 32.5 & 29.2 \\
\hline
\end{tabular}

BCVA best corrected visual acuity, CFT central foveal thickness, ERM epiretinal membrane, FTMH full thickness macular hole, IOP intraocular pressure, 25G 25-gauge, 27G 27-gauge, Surgical Time-Modified removed outlier of FTMH 27 G data 
logMAR BCVA improved from 0.34 $( \pm 0.28)$ to 0.24 $( \pm 0.25)(\mathrm{p}=0.029)$.

For 25G FTMH phakic patients only, mean logMAR BCVA improved from $0.93( \pm 0.48)$ to $0.69( \pm 0.53)$ $(\mathrm{p}=0.021)$. For $27 \mathrm{G}$ FTMH phakic patients only, mean $\log$ MAR BCVA changed from $0.88( \pm 0.63)$ to 1.00 ( \pm 0.59$)$. For $25 \mathrm{G}$ FTMH pseudophakic patients, mean $\log$ MAR BCVA improved from $0.81( \pm 0.48)$ to $0.33( \pm 0.20)(\mathrm{p}<0.001)$. For $27 \mathrm{G}$ FTMH pseudophakic patients, mean logMAR BCVA changed from 0.90 $( \pm 0.3)$ to $0.91( \pm 0.68)$.

For 25G ERMs, CFT reduced from 424.38 $( \pm 89.24 \mu \mathrm{m})$ to $358.58( \pm 61.8 \mu \mathrm{m})(\mathrm{p}<0.001)$ and $\mathrm{MV}$ reduced from $10.0( \pm 1.17) \mathrm{mm}^{3}$ to $8.86( \pm 0.76) \mathrm{mm}^{3}$ $(\mathrm{p}<0.001)$. For 27G ERMs, CFT reduced from 464.15 $( \pm 75.05) \mu \mathrm{m}$ to $394.37( \pm 42.76) \mu \mathrm{m}(\mathrm{p}<0.001)$ and $\mathrm{MV}$ reduced from $10.3( \pm 1.32) \mathrm{mm}^{3}$ to $9.08( \pm 0.66)$ $\mathrm{mm}^{3}(\mathrm{p}<0.001)$.

For ERMs, mean surgical time was 3.9 min shorter in the $27 \mathrm{G}$ group than in the $25 \mathrm{G}$ group $(\mathrm{p}<0.001)$. For $\mathrm{FTMH}$, there was one significantly longer case in the 27G cohort that skewed results disproportionately to the general data distribution for both 27G and 25G. A second analysis was done removing the one case from surgical time, Table 3 . Using the data with the one removed surgical time for $27 \mathrm{G}$, mean surgical time was 3.3 min shorter for 27G FTMH than 25G FTMH $(\mathrm{p}=0.04)$. There was no significant difference in IOP in any group post-operatively.

Overall, there were no serious intra-operative complications in any group and no cases of endophthalmitis were documented. Air-fluid exchange was used for incisional tamponade, while gas was used in ERM cases when a retinal tear was identified (Additional file 1: Table S1). There were more retinal tears (4:1) in the 25G:27G ERM group. However, the 25G group is a larger sample size and this study was not designed nor powered to assess statistical significance of intra-operative findings that did not alter primary or secondary outcomes (e.g. post-surgical retinal detachments or recurrence of macular membranes). None of the patients in the ERM group underwent repeat surgeries within 3 months. A total of three patients in the FTMH group required repeat surgery within 3 months. Two of these patients were in the 27G FTMH group, with one requiring surgery for a new FTMH and one requiring surgery for a recurrent non-closing FTMH. The patient in the 25G FTMH also had a recurrent non-closing FTMH. All three FTMH were successfully closed following a period of silicone oil tamponade.

\section{Discussion}

As expected, BCVA significantly improved for all patients combined. For ERM only, the final visual outcomes for $25 \mathrm{G}$ vs $27 \mathrm{G}$ presented here show that both groups ultimately achieve an almost identical mean BCVA (0.30 vs $0.28)(20 / 40$ vs 20/38). However, for the $27 G$ ERM group these findings were not statistically significant, which is most likely due to the difference in baseline BCVA $(0.51$ vs 0.33$)(20 / 65$ vs $20 / 43)$ resulting in a smaller magnitude of improvement. Interestingly, at baseline the 27G ERM group had a borderline statistically significant greater mean CFT, yet counterintuitively a significantly better mean pre-operative BCVA. This appears to be primarily driven by the difference between the 25G and 27G ERM pseudophakic sub-groups at baseline (Table 2). For the $25 \mathrm{G}$ vs $27 \mathrm{G}$ FTMH, only the $25 \mathrm{G}$ group achieved a statistically significant improvement in BCVA.

When stratified by lens status, pseudophakic patients typically achieved better post-operative BCVA outcomes, although a major component of this is likely attributable to the progression of cataract following vitreoretinal surgery in patients who were phakic pre-operatively. A further study may be beneficial to follow these patients for a longer post-operative window in order to capture BCVA outcomes following cataract extraction and IOL insertion after vitreoretinal surgery.

The significantly shorter mean surgical time demonstrated with $27 \mathrm{G}$ instrumentation for both ERM and FTMH is encouraging and could be partially attributed to the greater functionality associated with the $27 \mathrm{G}$ system versus the $25 \mathrm{G}$ system or the surgeon's greater ease at achieving wound closure after trocar removal with a smaller gauge. However, this does appear to contradict other studies that have generally demonstrated a small increase in surgical time with the 27G system [4, 19, 22].

The strict exclusion criteria chosen for this study may be considered as a limitation, given that $45 \%$ of identified cases were excluded. However, the underlying rationale aimed to minimize confounding variables and more accurately elucidate any effect of differing instrumentation gauge on safety and visual outcomes for both ERM and FTMH. Subsequently, the sample sizes for the 27G ERM and FTMH groups were reduced due to the large number of cases excluded. Evidently, the small sample size for the 27G FTMH group in particular poses difficulty in assessing statistical and clinical significance. Thus, more 27G FTMH cases are required to establish whether or not the statistically significant improvement in BCVA seen in the 25G FTMH cases translates to 27G. A recent study of 87 patients with macular holes demonstrated that over a 10 year follow-up period, BCVA continued to improve for 3 years before stabilizing following ILM peel surgery. It also identified that re-establishment of retina ellipsoid zone and 
the external limiting membrane on post-operative OCT were associated with better outcomes [23]. Longer timepoints in this study would plausibly be beneficial to determine the absolute benefit of these interventions.

At 6-month follow up, both 25G and 27G were safe and well tolerated MIVS platforms for the treatment of ERM and FTMH. Innovation and evolution are constant processes in medical science and technology, which translate to iterative improvements in surgical instrumentation. As such, there is inevitably a learning curve associated with becoming familiar with any new surgical platform and variability in technique between surgeons could also impact outcomes. While this dataset does not show a clear advantage to the newer 27G system, it is interesting to note that all of the retina surgeons in this practice have uniformly switched over to the smaller gauge system for a predominance of their surgical volume. Perhaps, the rationale for the change will become apparent in a prospective study, or a larger sample size with longer follow-up, but those remain to be performed. This study does confirm that for this retrospective series there is no significant difference in outcomes between the two most recent MIVS platforms for ERM and FTMH. Future efforts will be important to better elucidate any plausible significant differences.

\section{Supplementary information}

Supplementary information accompanies this paper at https://doi. org/10.1186/s40942-020-00259-4.

Additional file 1: Table S1. Intra-operative variables.

\section{Acknowledgements}

Not applicable.

This work was accepted for a poster presentation at ARVO 2020.

\section{Authors' contribution}

GB: data acquisition, manuscript drafting, statistical analysis. SP: conceptualized study design, substantial contribution to data acquisition. JK: conceptualized study design, edited manuscript. PK: conceptualized study design, edited manuscript. RB: conceptualized study design, edited manuscript. AH: conceptualized study design, statistical analysis, interpretation of data, edited manuscript. All authors discussed the work and contributed to the manuscript. All authors read and approved the final manuscript.

\section{Funding}

None.

\section{Availability of data and materials \\ Coded dataset available upon request.}

\section{Ethics approval and consent to participate}

This study was approved by PeaceHealth IRB, who granted a full waiver of informed consent. (Ref No.: 1335275)

\section{Consent for publication}

Not applicable.

\section{Competing interests}

The authors have no conflicts of interest or financial disclosures to declare.
Received: 18 May 2020 Accepted: 5 November 2020

Published online: 16 November 2020

\section{References}

1. Schönfeld CL. 23-vs 20-gauge pars plana vitrectomy in combination with bimanual microincisional cataract surgery (b-MICS) for the treatment of macular hole and cataract as a one-step procedure. Eye (Lond). 2013;27:952-8.

2. Wimpissinger $B$, Kellner $L$, Brannath $W$, et al. 23-gauge versus 20-gauge system for pars plana vitrectomy: a prospective randomised clinical trial. Br J Ophthalmol. 2008:92:1483-7.

3. Kim M, Park YS, Lee DH, et al. Comparison of surgical outcome of 23-gauge and 25-gauge microincision vitrectomy surgery for management of idiopathic epiretinal membrane in pseudophakic eyes. Retina. 2015;35:2115-20.

4. Lubiński W, Gosławski W, Podborączyńska-Jodko K, et al. Comparison of 27 -gauge versus 25 -gauge vitrectomy results in patients with epiretinal membrane: 6-month follow-up. Int Ophthalmol. 2020. https://doi. org/10.1007/s10792-019-01250-1.

5. Naruse Z, Shimada H, Mori R. Surgical outcomes of 27-gauge and 25-gauge vitrectomy day surgery for proliferative diabetic retinopathy. Int Ophthalmol. 2019;39:1973-80.

6. Kellner L, Wimpissinger B, Stolba U, et al. 25-gauge vs 20-gauge system for pars plana vitrectomy: a prospective randomised clinical trial. Br J Ophthalmol. 2007;91:945-8.

7. Patelli F, Radice P, Zumbo G, et al. 25-gauge macular surgery. Retina. 2007;27:750-4.

8. Li J, Liu SM, Dong WT, et al. Outcomes of transconjunctival sutureless 27-gauge vitrectomy for vitreoretinal diseases. Int J Ophthalmol. 2018;11:408-15.

9. Govetto A, Virgili G, Menchini F, et al. A systematic review of endophthalmitis after microincisional versus 20-gauge vitrectomy. Ophthalmology. 2013;120:2286-91.

10. Wykoff CC, Parrott MB, Flynn HW Jr, et al. Nosocomial acute-onset postoperative endophthalmitis at a university teaching hospital (2002-2009). Am J Ophthalmol. 2010;150:392-8.

11. Oshima Y, Kadonosono K, Yamaji H, et al. Multicenter survey with a systematic overview of acute-onset endophthalmitis after transconjunctival microincision vitrectomy surgery. Am J Ophthalmol. 2010;150:716-25.

12. Wu L, Berrocal MH, Arévalo JF, et al. Endophthalmitis after pars plana vitrectomy: results of the pan american collaborative retina study group. Retina. 2011;31:673-8.

13. Chen G, Tzekov R, Li W, et al. Incidence of endophthalmitis after vitrectomy: a systematic review and meta-analysis. Retina. 2019;39:844-52.

14. Oshima Y, Wakabayashi T, Sato T, et al. A 27-gauge instrument system for transconjunctival sutureless microincision vitrectomy surgery. Ophthalmology. 2009;117(93-102):e2.

15. Rizzo S, Barca F, Caporossi T, Mariotti C. Twenty-seven-gauge vitrectomy for various vitreoretinal diseases. Retina. 2015;35:1273-8.

16. Khan MA, Shahlaee A, Toussaint B, et al. Outcomes of 27 gauge microincision vitrectomy surgery for posterior segment disease. Am J Ophthalmol. 2016;161:36-43.

17. Sborgia G, Niro A, Sborgia L, et al. One-year outcomes of 27-gauge versus 25 -gauge pars plana vitrectomy for uncomplicated rhegmatogenous retinal detachment repair. Int J Retin Vitr. 2019;5:13. https://doi. org/10.1186/s40942-019-0164-0.

18. Mitsui K, Kogo J, Takeda H, et al. Comparative study of 27-gauge vs 25-gauge vitrectomy for epiretinal membrane. Eye. 2016;30:538-44

19. Rizzo S, Polizzi S, Barca F, et al. Comparative study of 27-gauge versus 25-gauge vitrectomy for the treatment of primary rhegmatogenous retinal detachment. J Ophthalmol. 2017;2017:6384985.

20. Romano MR, Cennamo G, Ferrara M, et al. Twenty-seven-gauge versus 25-gauge vitrectomy for primary rhegmatogenous retinal detachement. Retina. 2017;37:637-42.

21. Li J, Zhao B, Liu S, et al. Retrospective comparison of 27-gauge and 25-gauge microincision vitrectomy surgery with silicone oil for the treatment of primary rhegmatogenous retinal detachment. J Ophthalmol. 2018;2018:7535043. 
22. Naruse S, Shimada H, Mori R. 27-gauge and 25-gauge vitrectomy day surgery for idiopathic epiretinal membrane. BMC Ophthalmol. 2017;17:188.

23. Elhusseiny AM, Schwartz SG, Flynn HW Jr, Smiddy WE. Long-term outcomes after macular hole surgery. Ophthalmol Retina. 2020;4:369-76.

\section{Publisher's Note}

Springer Nature remains neutral with regard to jurisdictional claims in published maps and institutional affiliations.
Ready to submit your research? Choose BMC and benefit from:

- fast, convenient online submission

- thorough peer review by experienced researchers in your field

- rapid publication on acceptance

- support for research data, including large and complex data types

- gold Open Access which fosters wider collaboration and increased citations

- maximum visibility for your research: over 100M website views per year

At BMC, research is always in progress.

Learn more biomedcentral.com/submissions 